\title{
Psychology of the Gender-Equitable Environment: Research of Problems
}

\author{
Oksana M. Kikinezhdi ${ }^{1, *}$, Halyna Ya. Zhyrska², Ruslana S. Chip ${ }^{3}$, Yaroslava Z. \\ Vasylkevych $^{4}$ and Tamara V. Hovorun ${ }^{5}$
}

${ }^{1}$ Department of Psychology, Faculty of Pedagogics and Psychology, Ternopil Volodymyr Hnatiuk National Pedagogical University (TNPU), Ternopil, Ukraine

${ }^{2}$ Department of General Biology and Methodology of Natural Sciences Teaching, Faculty of Chemistry and Biology, Ternopil Volodymyr Hnatiuk National Pedagogical University (TNPU), Ternopil, Ukraine

${ }^{3}$ Department of Developmental Psychology and Counselling, Faculty of Pedagogics and Psychology, Ternopil Volodymyr Hnatiuk National Pedagogical University (TNPU), Ternopil, Ukraine

${ }^{4}$ Department of Psychology, Socio-Historical Faculty, Hryhorii Skovoroda University in Pereiaslav, Pereiaslav, Ukraine

${ }^{5}$ Jindal Institute of Behavioural Sciences (JIBS) of O. P. Jindal Global University (JGU), Sonipat, Haryana, India

\begin{abstract}
The purpose of our study was to perform a comparative analysis of the level characteristics of the subjective perception of the egalitarian psychological well-being of participants in the educational process in mono- and heterogender educational space. The study used qualitative and quantitative methods to measure the level of psychological safety and psychological protection of participants in the educational process. The study relied on a questionnaire that was adapted to identify three indicators: "integrated indicator of the attitude to the educational environment", "significant characteristics of the educational environment and the index of satisfaction with it", "index of psychological security of the educational environment". A pilot project that was developed on the basis of the Research Centre for Gender Education and Development of Pupils and Students of the National Academy of Educational Sciences of Ukraine determined the educational vectors for building the psychology of an egalitarian safe, educational environment. The analysis found significant differences in the value of the coefficient of psychological well-being of participants in the educational process in all three models of organization of educational space. The masculine model revealed statistically significant signs of subjective psychological distress in cadets compared to the other two models. The satisfaction of parents and teachers with the level of psychological security in a gender-homogeneous educational environment is quite high. The model which reflects the feminine principle of forming study groups is subjectively perceived by students as psychologically safe.
\end{abstract}

Keywords: Egalitarian (equal) education, gender-equitable environment, non-discriminatory environment, gender, students, teachers, safe environment, psychological security.

\section{INTRODUCTION}

The issue of gender-equitable [1] education and development is quite actively discussed in the education system of our time. This topic is not new in Ukraine, although teachers and methodologists have not yet paid due attention to it, while there are still schools of differentiated education in some countries of Western Europe and the United States [2]. In the last decade, the system of national education has been in search of optimal educational space models to meet the diverse demands of society to the end product of the educational process as an element of socialisation of the younger generation - young people ready for the effective society of today. It is no coincidence that the model of education, which is based on a gender-

*Address correspondence to this author at the Department of the Psychology, Faculty Pedagogics and Psychology, Ternopil Volodymyr Hnatiuk National Pedagogical University (TNPU), Ternopil, Ukraine; Tel: +38(0352)533958;

Fax: +38(0352)435880; E-mail: okkikinezhdi@gmail.com equitable, non-discriminatory principle, has appeared in the area of this research.

This egalitarian approach to teaching and education has received methodological and theoretical development in the works of domestic and foreign authors in the field of social psychology and cultural anthropology [3-6]. Particular attention should be paid to the new direction of research related to an individual's psychological security as a leading characteristic of the educational gender-equitable environment. In this environment, the understanding of the subjective well-being of an individual is reflected in the following thesis: the emotional and evaluative attitude of a student to his life, his personality, relationships with others.

Creating a gender-equitable educational environment involves the study of psychological security against all kinds of psychological violence. The 
criterion base for assessing the psychological safety of the educational environment are the features of the subjects of the educational process (students, teachers, education administrators), the content of education (as total integrity of knowledge, skills, and methods of obtaining knowledge), features of relations in dyads: student-student, student-teacher, teacheradministration $[7,8]$.

The leading feature of a gender-equitable safe environment is psychological security, which determines its developmental nature and allows modelling psychological and pedagogical conditions of education and development based on preservation and strengthening of mental health of students and teachers, use of principles, content, and methods of psychological and pedagogical support of gender socialisation of youth in the micro-, meso- and macroenvironment; identification of socio-pedagogical factors of partnership interaction of scholars, teachers, parents and the community based on "partnership pedagogy" and gender "matrix" of humanistic pedagogical heritage; development, testing and implementation of the system of gender-educational technologies in the educational environment of HEls.

In continuation, let us note that psychological security within the egalitarian environment can be considered through the prism of various criteria in the structure of educational interaction: the physical criterion involves the normative functioning of the human body and subjective sense of health through the prism of identifying one's gender; individualpsychological is considered through the adaptability of an individual to external influences, a positive attitude to the world, the ability to protect themselves from various manipulative practices based on gender differences; personality level reflects a person's socioemotional experiences that are actualized in response to events that pose a potential or real threat to the security and integrity of an individual or people significant to individuals in case of neglecting gender equality [9-11].

We consider the egalitarian-educational environment as non-discriminatory, creative-developmental and health-preserving, based on the principles of social justice, gender equality, child-centeredness, which ensure full development of personality [12], regardless of gender, age capacity, race, culture, religion, ethnicity, etc., the future life trajectory of a person [13].

Speaking about the consideration of gender peculiarities in the process of creating an egalitarian environment in the Free Economic Zone, it is necessary to explain the meaning of the term "gender". Following the tradition of English-language research literature, modern scholars use the term "gender" to denote a huge area of interdisciplinary research. Gender is used to mean "social gender" as opposed to "biological gender". In general, the gender approach assumes that differences in behaviour, perception, and thinking of men and women are determined not only by their psychophysiological characteristics but also by social factors, such as education in the manner of ideas about the function of men and women common in each culture [14, 15].

Educators and psychologists who deal directly with this problem emphasise the need to select the content, methods, and forms of education according to the gender of students $[16,17]$. After all, the educational success of a future specialist, the formation of his personality in general largely depends on the extent to which the requirements of higher education will be adequate to the capabilities of girls and boys $[18,19]$.

The psychology of the gender-equitable environment, in contrast to other approaches in education, is based on the fact that not impersonal students enter HEls but girls and boys. This approach pays more attention to the individuality of each student, there is a focus on the personality of a future specialist, and, as a result, improves the microclimate in the group, in other words, maintains and increases the level of psychological security in the learning process $[20,21]$.

In the general sense, the psychological security of the educational environment is the state of security of a pupil/student protecting them from threats to his emotional comfort, dignity, positive worldview and attitude to himself. Psychological security is the most important condition for the full development of a student to strengthen and maintain his psychological health. Psychological health, in turn, is the basis of students' life, who has to solve difficult problems of his life in adolescence: to control their behaviour in accordance with gender requirements, learn to live, study, work and take responsibility for themselves and others taking into account gender differences, acquire a set of scientific knowledge and social skills, develop personal abilities and form their own self. Since mental health is an essential condition for success in life and a guarantee of human well-being, we believe that the creation of an egalitarian educational environment based on the principles of equality and nondiscrimination is a requirement of the time. 
Concern for the psychological health and comfort of students has now become a mandatory guideline in the work of every educational institution and teacher. Therefore, the psychology of a gender-equitable educational environment is based on the need to ensure health-preserving learning conditions, regardless of gender, religion, personal beliefs, and views of a student. Currently, a large number of future specialists experience unstable, uncomfortable conditions that lead to difficulties in meeting the requirements of higher education, more and more often students experience difficulties in communicating with teachers and peers. The solution to this problem is to achieve students' gender comfort as a state and qualitative feature of their activities.

The comfortable egalitarian environment of HEls is the internal space of an educational institution, a set of conditions that allow preserving the psychological and physical health of students, promote optimal inclusion of students in educational activities, their successful self-realization regardless of gender, age, capacity, race, culture, religion, ethnicity, etc. In the educational environment, achieving comfort as a psychophysiological state is a condition for successful adaptation of a student to new living conditions, emotional stability, active and proactive position, self-regulation, lack of anxiety, reduction of fatigue. The psychological comfort of a student contributes to the maximum preservation of his health, adequate behaviour, and successful educational activities, maintains a positive emotional background, forms a lasting sense of satisfaction from being in the higher educational institution. Psychological, intellectual, and physical comfort are structural components of gender comfort, and their commonality in the educational process is a condition for the full personal growth of a student $[22,23]$.

The purpose of our study is a comparative analysis of the level characteristics of the subjective perception of the egalitarian psychological well-being of participants in the educational process in mono- and heterogender educational space. It relies on the assumption that there is a relationship between gender factors embedded in a particular educational space model and a subjective assessment of the egalitarian psychological security of participants in the educational process.

\section{MATERIALS AND METHODS OF RESEARCH}

This was an explorative study that had used an adapted questionnaire to collect data. The questionnaire was modified by the employees of the
Research Center for Gender Education and Development of Pupils and Students of the National Academy of Educational Sciences of Ukraine at TNPU. It was a questionnaire entitled "Psychological Diagnosis of Safety of the School Educational Environment" [24], which allowed assessing qualitatively and quantitatively the level of psychological safety and psychological protection of participants in the educational process. The adapted questionnaire was focused on identifying three indicators: "integrated indicator of the attitude to the educational environment", "significant characteristics of the educational environment and the index of satisfaction with it", "index of psychological security of the educational environment". The third indicator most fully meets the goals and objectives of our study, which reflects the subjective experiences of the subjects of the educational process and allows assessing the psychological, egalitarian, and social well-being of an individual, the level of satisfaction with his sociopsychological status. The ratio of socially acceptable parameters of public gender status of an individual and his psychological stability associated with the harmonisation of feelings and emotions in the educational space was determined by a conditional quantitative indicator such as the factor of psychological well-being.

\section{Projects Description}

The first model was presented by a professionally specialised institution of higher military education in Odessa, where groups are formed on a tender basis and assume masculinity in the behaviour of applicants in the context of civic and patriotic education as priority characteristics of cadets. At the Military Academy, cadet groups are characterised by gender uniformity $95 \%$ of students were boys.

The second model is implemented on the basis of the Private Higher Educational Institution "Medical College". The specialty "Nursing" was chosen for the research. This decision is dictated by the achievement of homogeneity of the group - the vast majority of applicants (96\%) for nursing education are girls. The third model can be considered a classic form of the traditional education of students in mixed groups (TNPU). The study involved students, parents, and teachers of the said educational institutions (Table 1).

\section{Sample}

The study used randomised sampling technique aimed to involve three groups of individuals from three 
Table 1: Description of the Research Sample

\begin{tabular}{|c|c|c|c|}
\hline Model of organization of the educational process & Students & Parents & Teachers \\
\hline \hline Cadet groups (masculine) & 84 & 56 & 19 \\
\hline Medical College (Feminine) Groups & 86 & 32 & 24 \\
\hline Heterogender groups (traditional) & 81 & 26 & 31 \\
\hline Total & 251 & 114 & 72 \\
\hline
\end{tabular}

educational institutions with different models of organization of the educational process: Odesa Military Academy; TNPU; Private Higher Educational Institution "Medical College": students $(n=251$, age $16-22$ years, (64\% of them were young men)), parents of students $(n=114,(86 \%$ of them were mothers $))$, teachers $(n=72$, (92\% of women)) (see Table 2 ).

\section{Ethical Considerations}

Before the study, the participants provided informed consent to address the related ethical issues and their agreement to participate in the experiment on a voluntary base. The participants accepted that they allowed processing and making public their personal data in quantity needed for the experiment.

\section{Instruments}

The study relied on the adapted questionnaire. The method of expert assessment of the content of the questions was used to assign the question to one of the two groups of statements. The focus group of experts on egalitarian psychological security of the educational environment was represented by the staff of the Research Centre for Gender Education and Development of Pupils and Students of the National Academy of Educational Sciences of Ukraine at TNPU,

Table 2: Demographic Characteristics of the Sample $(n=437)$

\begin{tabular}{|c|c|c|c|c|}
\hline \multicolumn{2}{|c|}{ Characteristics } & & $\%$ & $p$ \\
\hline \multirow[t]{2}{*}{ Gender } & Males & & 64 & \multirow{2}{*}{$P<0.001$} \\
\hline & Females & & 36 & \\
\hline \multirow[t]{8}{*}{ Age } & \multirow[t]{4}{*}{ Males } & 16-22 & 64 & \multirow{4}{*}{0.117} \\
\hline & & 23-34 & 25 & \\
\hline & & $35-45$ & 17 & \\
\hline & & $46-60$ & 74 & \\
\hline & \multirow[t]{4}{*}{ Females } & $16-22$ & 36 & \multirow{4}{*}{0.162} \\
\hline & & $23-34$ & 85 & \\
\hline & & $36-45$ & 83 & \\
\hline & & $46-60$ & 16 & \\
\hline \multirow[t]{4}{*}{ Teacher Experience } & $2-10$ years & & 18 & \multirow{4}{*}{0.677} \\
\hline & $11-15$ years & & 54 & \\
\hline & $16-20$ years & & 16 & \\
\hline & $>21$ years & & 12 & \\
\hline \multirow{7}{*}{$\begin{array}{l}\text { Subject, a branch of knowledge } \\
\text { they teach }\end{array}$} & \multicolumn{2}{|c|}{ Languages and Literature } & 21 & \multirow{7}{*}{0.782} \\
\hline & \multicolumn{2}{|c|}{ Maths and Physics } & 17 & \\
\hline & \multicolumn{2}{|c|}{ Chemistry and Biology } & 4 & \\
\hline & & & 4 & \\
\hline & \multicolumn{2}{|c|}{ Physical Education } & 4 & \\
\hline & \multicolumn{2}{|c|}{ Medicine } & 23 & \\
\hline & \multicolumn{2}{|c|}{ Military subjects } & 27 & \\
\hline
\end{tabular}


teachers of TNPU, the parent community and representatives of the education management system. The focus group participants were asked questions, the structure of which provided for the identification of two levels of actualisation of the problem of creating an egalitarian non-discriminatory environment in $\mathrm{HEI}$ to ensure psychological safety of the subjects of education: the level of public expectations, or the "formal" section of the attitude to the problem, and the level of personal attitude to the egalitarian educational environment, or the "subjectively significant" section. The first group included general questions that required an assessment of the overall quality of the relationship with teachers, students, parents, colleagues, or the administration, depending on the group of respondents. The second group combined situational issues in which the respondent assesses his subjective indicators of psychological gender security, such as the threat of public humiliation, insults, ridicule, ignoring.

The ratio of "formal" and "subjectively significant" answers forms the factor of psychological well-being (PWB). After the scales were combined into a single questionnaire, a reliability test was performed using the Cronbach coefficient, which allows establishing the internal consistency of the scales describing the sample. The analysis included data from a sample of 108 people. Statistical verification showed that at the significance level of $p<0.01$, the Cronbach's coefficient is 0.81 . This figure is high, which indicates the reliability of the questionnaire. Each variant of the selected answers was assigned a score from one to five, depending on the extent to which the respondent is satisfied with each of the selected characteristics and how secure he feels in the high school's educational space. To identify differences in the indicators of the coefficient of the psychological well-being of the studied samples, a comparative analysis was performed according to the Mann-Whitney U-test using the software package SPSS Statistics 20.

\section{RESULTS}

The obtained data set allowed identifying three groups of respondents, differing in the severity of PWB. The answers, in which the coefficient of psychological well-being was estimated at 15 to 35 points, were classified as "at-risk" and attributed to the first group. The results from 36 to 55 points were combined into the second group: the psychological security of respondents in this group is defined as pronounced adaptability to the educational environment and is seen as the relative egalitarian well-being of an individual in the educational space. The third group consisted of respondents whose psychological well-being coefficient was higher than 56 points, which characterises a comfortable, safe state of an individual and can be considered optimal for a person institutionalised in the educational system (Table $\mathbf{3}$ ).

The data of Table 3 show significant differences in the total indicator of psychological well-being of cadets and future nurses $(i=928 ; p<0.05)$, cadets and traditional student groups $(i=872 ; p<0.001)$, future nurses and students of mixed groups $(i=841 ; p<0.001)$.

The group comparative analysis revealed statistically significant differences in the level of socially acceptable responses in the studied samples of cadets and future nurses ( $i=56 ; p<0.01)$, students of mixed groups, and future nurses $(i=24 ; p<0.01)$.

According to the obtained data, a monogender learning environment can be considered comfortable from the standpoint of students, which provides for the reduction of subjective risks of interaction in the educational process. However, this group of respondents has the largest number of socially acceptable responses, which suggests the impact on the result of the situational variable associated with increased attention to the groups participating in the experimental study.

Table 3: Comparative Analysis of the Coefficient of Psychological Well-Being in the Sample of Students

\begin{tabular}{|c|c|c|c|c|c|c|c|c|c|}
\hline \multirow{3}{*}{$\begin{array}{c}\text { Model of organization of the educational } \\
\text { process }\end{array}$} & \multicolumn{9}{|c|}{ The level of psychological well-being } \\
\hline & \multicolumn{3}{|c|}{ Lover than average } & \multicolumn{3}{|c|}{ Average } & \multicolumn{3}{|c|}{ High } \\
\hline & $n$ & AVPWB & $\sigma$ & $n$ & AVPWB & $\sigma$ & $n$ & AVPWB & $\sigma$ \\
\hline Cadet groups (masculine) & 14 & 21.34 & 5.3 & 50 & 42.67 & 1.6 & 10 & 60.56 & 3.1 \\
\hline Medical College (Feminine) Groups & 4 & 30.02 & 7.1 & 64 & 51.08 & 4.7 & 18 & 66.27 & 1.8 \\
\hline
\end{tabular}

Note. $\mathrm{n}$ - number of the subjects; AVPWB - the average value of the coefficient of psychological well-being; $\sigma$ - standard deviation. 
Table 4: Comparative Analysis of the Coefficient of Psychological Well-Being in the Sample of Teachers

\begin{tabular}{|c|c|c|c|c|c|c|c|c|c|}
\hline \multirow{3}{*}{$\begin{array}{l}\text { Model of organization of the educational } \\
\text { process }\end{array}$} & \multicolumn{9}{|c|}{ The level of psychological well-being } \\
\hline & \multicolumn{3}{|c|}{ Lover than average } & \multicolumn{3}{|c|}{ Average } & \multicolumn{3}{|c|}{ High } \\
\hline & $n$ & AVPWB & $\sigma$ & $n$ & AVPWB & $\sigma$ & $n$ & AVPWB & $\sigma$ \\
\hline Cadet groups (masculine) & 2 & 28 & 2.5 & 5 & 49 & 4.6 & 10 & 65 & 1.7 \\
\hline Medical College (Feminine) Groups & 2 & 33 & 2.2 & 10 & 52 & 2.8 & 11 & 68 & 1.5 \\
\hline Heterogender groups (traditional) & 4 & 32 & 2.2 & 21 & 50 & 2.8 & 8 & 70 & 1.3 \\
\hline
\end{tabular}

Note. See the designations for Table 3.

Cadets of the Military Academy demonstrated a low level of subjective well-being, a large number of socially acceptable responses more often than others, which may indicate the formalization of ways of interaction with "external" agents of the social environment and the formation of fundamentally different systems of "coding" corresponding to the specifics of the military communication environment.

The data given in Table 4 indicate the absence of statistically significant differences in the assessment of the level of psychological well-being of teachers working according to three educational models.

For the interviewed teachers, the motivation of interaction in the egalitarian educational space is related to the sphere of professional activity and to building network social relations - gender-equitable, formal or informal, within the framework determined, first of all, by the requirements of professional activity. We can assume that the psychological well-being of a teacher in a non-discriminatory environment will primarily be associated with the comfort of professional activity.

Group comparative analysis revealed statistically significant differences in the level of socially acceptable responses in teachers working at the Military Academy and in mixed traditional groups of TNPU ( $i=14 ; p<0.05)$; teachers of the Military Academy and teachers of the Medical College $(i=29 ; p<0.05)$, as well as teachers of the Medical College and those who work in the traditional conditions of mixed groups $(i=18 ; p<0.05)$. It follows that the teacher is included in the institutionalised component of the egalitarian educational environment more than other participants in the educational process (parents, administration). The outlined environment is of interest to teachers, first of all, as a sphere of professional self-realization and may slightly affect domestic, intimate, microgroup contexts in which he is involved outside the educational institution and those communication systems that exist within these contexts.

However, the data obtained (Table 5) indicate significant differences in the total psychological wellbeing of parents in three comparable groups: parents of cadets and future nurses ( $i=117 ; p<0.05)$, parents of cadets and parents of students of traditional mixed groups ( $i=107 ; p<0.05)$; parents of students of the Medical College and subjects who study at TNPU according to traditional methods $(i=131 ; p<0.05)$.

Group comparative analysis revealed significant differences only among groups of "dissatisfied" parents. Thus, in the first group, where the level of subjective psychological well-being is below average, the following data were obtained: parents of cadets and parents of future nurses ( $i=16 ; p<0.05)$, parents of cadets and students of mixed groups of TPNU ( $i=48$; $p<0.05$ ); parents of students of the Medical College and mixed groups $(i=23 ; p<0.05)$.

Table 5: Comparative Analysis of the Coefficient of Psychological Well-Being in the Sample of Parents

\begin{tabular}{|c|c|c|c|c|c|c|c|c|c|}
\hline \multirow{3}{*}{$\begin{array}{l}\text { Model of organization of the educational } \\
\text { process }\end{array}$} & \multicolumn{9}{|c|}{ The level of psychological well-being } \\
\hline & \multicolumn{3}{|c|}{ Lover than average } & \multicolumn{3}{|c|}{ Average } & \multicolumn{3}{|c|}{ High } \\
\hline & $n$ & AVPWB & $\sigma$ & $n$ & AVPWB & $\sigma$ & $n$ & AVPWB & $\boldsymbol{\sigma}$ \\
\hline Cadet groups (masculine) & 10 & 33 & 1,8 & 38 & 51 & 4,0 & 8 & 70 & 2,8 \\
\hline Medical College (Feminine) Groups & 8 & 31 & 1,5 & 16 & 48 & 2,3 & 8 & 62 & 2,5 \\
\hline Heterogender groups (traditional) & 12 & 23 & 4,5 & 14 & 51 & 2,5 & 5 & 65 & 2,7 \\
\hline
\end{tabular}

Note. See the designations for Table 3. 
The parental position is diametrically opposed to the position of teachers. Social networks in which parents are included in the context of their professional activities, in the intimate, friendly, neighbourhood, etc. contexts are in no way (in most cases) related to the educational institution. Thus, the educational organization for them is an external institution they are forced to interact with - just as an institution that is only later represented by particular people and, accordingly, systems of personalized relationships built in the course of this interaction.

A high level of psychological well-being was found in the answers of parents whose children study at the Medical College, which indicates the lack of communicative and emotional tension in interaction with the educational space. This group of surveyed parents showed the highest percentage of socially acceptable responses.

The parents of the cadets demonstrated the average adaptive level of psychological well-being in relation to the school. It can be assumed that the monogender structure of the educational environment is adequately assessed by parents, meets their expectations, and does not create a gap of uncertainty in interaction with the educational environment. Summing up, we note that for teachers, the educational egalitarian non-discriminatory space is, first of all, a sphere of professional institutionalization, while for parents - the institutionalization of a "residual". A student occupies an intermediate position in this relationship. On the one hand, he is included in this field according to the rules of the game: educational activities are binding on him, that is, the very situation of involvement does not depend on his control. The egalitarian identity that the student is forced to build here is formed primarily under the influence of external factors and only secondarily - based on the factors of "internal design". The identity that can be built independently is associated with the "pockets" of alternative communication, creating alternative networks of social relationships.

\section{DISCUSSION}

The study aimed to explore the characteristics level of subjective perception of the egalitarian psychological well-being of participants in the educational process in mono- and heterogender educational space. The novelty of this study lies in finding the relationship between the model of traditional mixed education with its average (adaptive) level of subjective well-being of students which is more common than in the other two, which indicates more complex adaptive strategies assimilated by future teachers, and here socially acceptable answers are not as common as in groups of future nurses. The results go in line with previous research stating that the sources of psychological comfort in the framework of a specially designed egalitarian educational environment are primarily organisational and communicative conditions, i.e., the organisation of interpersonal interaction of subjects. Speaking of the "teacher-student" system, we mean relationships in the process of joint educational activities, which are expressed in a positive emotional state. In a personal sense, it is expressed in empathic acceptance of each other, active listening, and trust. It is a prerequisite that a teacher needs to have the skills of empathic listening, the purpose of which is to ensure a sense of respect.

Resorting to separate learning as a model of educational space, where students' psychological safety is ensured by reducing risks through creating a monogender environment, requires clarification and study of the processes of social adaptation in such conditions. On the one hand, the monogender approach to the education of the younger generation is an integral part of the world's educational tradition, and it is associated with the beginning with the very concept of education in ancient Greek and Roman cultures, laying the foundations of European civilization [23]. On the other hand, the communities and systems of social practices to which traditional monogender education has been directed were built themselves on foundations that differ significantly from those on which their modern counterparts are based [ 25, 26]. Thus, archaic Indo-European systems of education did not involve the gradual adaptation of adolescents to adulthood and, accordingly, the step-by-step formation of "adult" gender skills of self-control, social responsibility, and empathy, raising the threshold of aggression, but rather encouraging behaviours that would be now recognized as deviant, against the background of total social, food, sexual deprivation with a subsequent threshold transition to adulthood, when the previous experience is segmented as unacceptable in the "adult" public space [27].

This is the basis of such a traditional institution as youth men's unions, the relics of which still play an extremely important role in the self-organization of monogender social environments [28]. Therefore, it would be very careless not to take into account this "background institutional memory" in the formation of 
monogender educational spaces in modern conditions [29].

The strategies of upbringing and maturation specific for modern European-type communities, institutionalised in public and private education systems, as well as in a number of individual practices that coexist with these systems (tutoring, homeschooling, etc.) form a field of social ties in which one way or another, almost every modern person is involved in particular role positions. In the most general form, the positions proposed by this field can be divided into three groups: "teacher", "student" and "administrator". For these three groups, certain positional niches have been formed within the higher school, which, in turn, are associated with some gender, social and behavioural stereotypes, lines of social status, systems of distribution of symbolic capital, and so on. These groups differ primarily in the degree and ways of controlling situations that arise both within their own niches and in the wider field, in the degree of responsibility for these situations, in the ways of constructing their own and others' genderequitable identities within the educational space [30].

For each of these groups, being in this field and participating in the situations of interaction they define are associated with fundamentally different systems of motivation, correlated with different systems of values, hierarchies, and determine the level of subjective gender-non-discriminatory psychological security [31].

Therefore, we found and proved that the psychology of egalitarian educational environment is based on creating conditions for the formation of relations between the genders, free from ingrained stereotypes of masculinity and femininity in the traditional patriarchal sense, which will significantly increase the psychological security of students in the educational process and will be the key to the education of a new individual open to different cultures, with the priorities of peace and equality in all spheres of life, a wide range of personal life choices and self-realisation.

\section{CONCLUSIONS}

The psychology of a gender-equitable environment, in contrast to other education approaches, is based on the fact that girls and boys enter HEls, not impersonal students. In a general sense, the psychological security of the educational environment in the state of security of pupils/students from threats to their emotional comfort, dignity, positive worldview, and attitude to themselves. It seems obvious that psychological security is the most important condition for students' full development to strengthen and maintain their psychological health. The key to achieving the participants' psychological comfort in the educational process is to create an equal environment. To this end, an attempt was made to identify psychological and pedagogical mechanisms for creating a genderequitable environment for children and youth as nondiscriminatory, creative, developmental, and healthpreserving to harmonize personal, professional, and civic growth of students. To achieve this goal, the current state of students' psychological comfort studying according to different egalitarian educational models was studied.

The conducted analysis allowed establishing significant differences in the value of the coefficient of psychological well-being of participants in the educational process in all three models of organization of educational space. The masculine model revealed statistically significant signs of subjective psychological distress in cadets compared to the other two models. At the same time, parent's and teachers' satisfaction with the level of psychological security in a genderhomogeneous educational environment is quite high. The model which reflects the feminine principle of forming study groups is subjectively perceived by students as psychologically safe. However, a significant number of parents with a low level of subjective well-being and hidden concerns about the educational institution were found in this group.

According to the study results, the model of traditional mixed education looks attractive in terms of the psychological security of the educational environment for all three groups of respondents students, teachers, and parents. It should be noted for teachers that the psychological security of a nondiscriminatory educational environment does not correlate with the gender aspect of the formation of educational space and is part of professional selfrealization, regardless of whether the student group is mixed or homogeneous in terms of gender. The practical conclusion of the study is in the relationship of gender factors inherent in different models of educational space and the degree of psychological security felt by participants in the educational process at the level of subjective assessment, as well as in need to consider this factor in organising egalitarian non-discriminatory safe, educational environment. 


\section{PROSPECTS FOR FURTHER RESEARCH}

The study does not cover all the problems of creating an egalitarian non-discriminatory environment in educational institutions. At the same time, this research is limited to the specific conditions of the study: the specifics of the organisation of the educational process at the Military Academy, TNPU and Private Higher Educational Institution "Medical College"; selected sample (students ( $n=251$, age 16-22 years, $(64 \%$ - young men)), parents of students $(n=114, \quad(86 \%$ - mothers $))$, teachers $(n=72, \quad(92 \%$ women)).

Further research is needed to address the effectiveness of the implementation of gendereducational technologies which involves achieving "equality of results" based on the integration of two principles - "equal access" and "equal treatment", which means revealing the individual potential of young people regardless of gender; fundamentalization of the gender ideology of educational practices as a strategic direction of the state policy of egalitarianism; and dogmatization of methodological principles of personality-egalitarian approach as a leading mechanism of gender self-determination.

\section{ACKNOWLEDGEMENT}

We express our gratitude to all the participants and people involved in this study for making it smooth and fruitful.

\section{CONFLICTS OF INTEREST}

The authors declare no conflict of interest related to commercial, legal, financial, or any other opposing interests that may affect this study.

\section{REFERENCES}

[1] Kikinezhdi OM. Gender identity in the ontogenesis of the personality: monograph. Ternopil: "The Teaching book Bogdan"; 2011.

[2] U.S. Department of State. Fact sheet: Promoting gender equality to achieve our national security and foreign policy objectives. Washington, DC; 2012. [cited 2020 Jun 8]: Available from https://2009-2017.state.gov/s/gwi/rls/ other/2012/187001.htm

[3] Marushchenko O, Andrusyk O, Drozhzhyna T., editors. Gender pedagogical almanac. Kharkiv: Planet - Print; 2017.

[4] Alexander GM, Wilcox T. Sex differences in early infancy. Child Dev Perspect 2012; 6: 400-6. https://doi.org/10.1111/j.1750-8606.2012.00247.x

[5] Bleidorn W, Arslan RC, Denissen JJA, Rentfrow PJ, Gebauer JE, Potter J, Gosling SD. Age and gender differences in selfesteem - A cross-cultural window. J Pers Soc Psychol 2016; 111(3): 396-410.

https://doi.org/10.1037/pspp0000078
Conroy-Beam D, Buss DM, Pham MN, Shackelford TK. How sexually dimorphic are human mate preferences? Personality and Social Psychology Bulletin 2015; 41: 1082-93. https://doi.org/10.1177/0146167215590987

[7] Sharma RR, Sharma NP. Opening the gender diversity black box: causality of perceived gender equity and locus of control and mediation of work engagement in employee well-being. Front Psychol 2015; 6: 1371. https://doi.org/10.3389/fpsyg.2015.01371

[8] Williams P, Kern ML, Waters L. Exploring selective exposure and confirmation bias as processes underlying employee work happiness: an intervention study. Front Psychol 2016; 7: Article 878

https://doi.org/10.3389/fpsyg.2016.00878

[9] Hill PW, McQuillan J, Talbert E, Spiegel A, Gauthier G Diamond J. Science possible selves and the desire to be a scientist: Mindsets, gender bias, and confidence during early adolescence. Social Sciences 2017; 6(2): 55-73. https://doi.org/10.3390/socsci6020055

[10] Moller S, Stearns E, Southworth S, Potochnick S. Changing course: The gender gap in college selectivity and opportunities to learn in the high school curriculum. Gend Educ 2013; 25(7): 851-71. https://doi.org/10.1080/09540253.2013.853028

[11] Morales DX, Grineski SE, Collins TW. Effects of gender concordance in mentoring relationships on summer research experience outcomes for undergraduate students. Science Education 2018; 102(5): 1029-50.

https://doi.org/10.1002/sce.21455

[12] Kravets VP, Kikinezhdi OM, Shulha IM. To the problem of humanization of the educational space of the modern Ukrainian school. Osvitolohiya 2018; 7: 15-21.

https://doi.org/10.28925/2226-3012.2018.7.1521

[13] Hovorun T, Kikinezhdi O. Gender Psychology. Kyiv: Vydavnychyj centr "Akademija"; 2004.

[14] Aikman S, Halai A, Rubagiza J. Conceptualising gender equality in research on education quality. Comp Educ 2011; 47(1): 45-60. https://doi.org/10.1080/03050068.2011.541675

[15] Berekashvili $N$. The role of gender-biased perceptions in teacher-student interaction. J Child Lang 2012; 16(1): 39-51. https://doi.org/10.2478/v10057-012-0004-x

[16] Damarin S, Erchick DB. Toward clarifying the meanings of "gender" in mathematics education research. J Res Math Educ 2010; 41(4): 310-23.

[17] Todor I. Gender in education: Teacher's perspective. The International Journal of Interdisciplinary Social Studies 2010; 4(12): 45-52.

https://doi.org/10.18848/1833-1882/CGP/v04i12/53047

[18] Namtip A, comp. Gender sensitivity: A training manual for sensitizing education managers, curriculum and material developers and media professionals to gender concerns. Paris: UNESCO; 2004.

[19] Unterhalter E, North A. Responding to the gender and education Millennium Development Goals in South Africa and Kenya: Reflections on education rights, gender equality, and global justice. Compare: A Journal of Comparative and International Education 2011; 41(4): 495-511. https://doi.org/10.1080/03057925.2011.581516

[20] Carlone HB, Scott CM, Lowder C. Becoming (less) scientific: A longitudinal study of students' identity work from elementary to middle school science. Journal of Research in Science Teaching 2014; 51(7): 836-69. https://doi.org/10.1002/tea.21150

[21] Donovan BM, Stuhlsatz MAM, Edelson DC, Buck Bracey ZE Gendered genetics: How reading about the genetic basis of sex differences in biology textbooks could affect beliefs associated with science gender disparities. Science Education 2019; 103(4): 719-49. https://doi.org/10.1002/sce.21502 
[22] Olsson A, Kopsida E, Sorjonen K, Savic I. Testosterone and estrogen impact social evaluations and vicarious emotions: A double-blind placebo-controlled study. Emotion 2016; 16(4): 515-23.

https://doi.org/10.1037/a0039765

[23] Schmitt DP. The evolution of culturally-variable sex differences: Men and women are not always different, but when they are ...it appears not to result from patriarchy or sex role socialization. In: VA Weekes-Shackelford, TK Shackelford, editors. The evolution of sexuality. New York, NY: Springer 2015; p. 221-56. https://doi.org/10.1007/978-3-319-09384-0 11

[24] Burke RJ. The Sandwich generation: Individual, family, organizational and societal challenges and opportunities. The Sandwich generation: Caring for oneself and others at home and at work. Cheltenham: Edward Elgar Publishing; 2017.

[25] Fischer R, Schwartz S. Whence differences in value priorities? Individual, cultural, or artifactual sources. J Cross Cult Psychol 2011; 42: 1127-44. https://doi.org/10.1177/0022022110381429

[26] Grijalva E, Newman DA, Tay L, Donnellan MB, Harms PD, Robins RW, Yan T. Gender differences in narcissism: A meta-analytic review. Psychological Bulletin 2015; 141(2): 261-310. https://doi.org/10.1037/a0038231
[27] Zell E, Krizan Z, Teeter SR. Evaluating gender similarities and differences using metasynthesis. American Psychologist 2015; 70: 10-20. https://doi.org/10.1037/a0038208

[28] Zentner M, Eagly AH. A sociocultural framework for understanding partner preferences of women and men: Integration of concepts and evidence. Eur Rev Soc Psychol 2015; 26: 328-73. https://doi.org/10.1080/10463283.2015.1111599

[29] Ngo HY, Foley S, Ji MS, Loi R. Linking gender role orientation to subjective career success: the mediating role of psychological capital. J Career Assess 2014; 22(2): 290-303. https://doi.org/10.1177/1069072713493984

[30] David SA, Boniwell I, Ayers AC. In: The Future of Happiness," in David SA, Boniwell I, Ayers AC, editors. Oxford Handbook of Happiness. Oxford: Oxford University Press 2013; p. 1067-71. https://doi.org/10.1093/oxfordhb/9780199557257.001.0001

[31] Drummond S, O'Driscoll MP, Brough P, Kalliath T, Siu OL, Timms C, Riley D, Sit C, Lo D. The relationship of social support with well-being outcomes via work-family conflict: moderating effects of gender, dependants and nationality. Human Relations 2017; 70: 544-65. https://doi.org/10.1177/0018726716662696

DOI: https://doi.org/10.6000/2292-2598.2020.08.03.31

(C) 2020 Kikinezhdi et al.; Licensee Lifescience Global.

This is an open access article licensed under the terms of the Creative Commons Attribution Non-Commercial License (http://creativecommons.org/licenses/by-nc/3.0/) which permits unrestricted, non-commercial use, distribution and reproduction in any medium, provided the work is properly cited. 